\title{
Sexual harassment in Dentistry: prevalence in dental school
}

\author{
Cléa Adas Saliba GARBIN ${ }^{1}$, Lívia Guimarães ZINA², Artênio José Insper GARBIN³, Suzely Adas Saliba MOIMAZ³
}

1-DDS, MSc, PhD, Associate Professor, Discipline of Bioethics, Department of Pediatric and Community Dentistry, Araçatuba Dental School, São Paulo State University, Araçatuba, SP, Brazil.

2-DDS, MSc, PhD, Postgraduate Program in Preventive and Community Dentistry, Araçatuba Dental School, São Paulo State University, Araçatuba, SP, Brazil.

3-DDS, MSc, PhD, Associate Professor, Department of Pediatric and Community Dentistry, Araçatuba Dental School, São Paulo State University, Araçatuba, $\mathrm{SP}$, Brazil.

Corresponding address: Cléa Adas Saliba Garbin - Departamento de Odontologia Infantil e Social - Faculdade de Odontologia de Araçatuba - Universidade Estadual Paulista - Rua José Bonifácio, 1193 - Araçatuba - SP - 16015-050 - Phone: 55 (18) 3636 3249/ Fax: 55 (18) 36363332 - e-mail: cgarbin@foa.unesp.br

Received: March 2, 2009 - Modification: August 1, 2009 - Accepted: October 22, 2009

\section{ABSTRACT}

\begin{abstract}
O bjective: Sexual harassment is unlawful in all work and educational environments in most nations of the world. The goals of this study were to describe the sexual harassment prevalence and to evaluate the experiences and attitudes of undergraduate students in one dental school in Brazil. Material and Methods: An 18-item questionnaire was administered to 254 dental students with a completion rate of $82 \%$ (208). Students were requested to respond to questions about their background and academic level in dental school, their personal experiences with sexual harassment and their observation of someone else being sexually harassed. Bivariate statistical analyses were performed. Results: Fifteen percent of the students reported being sexually harassed by a patient, by a relative of a patient or by a professor. Male students had 3 times higher probability of being sexually harassed than female student $[\mathrm{OR}=2.910(1.113-7.611)]$. Additionally, $25.4 \%$ of the students reported witnessing sexual harassment at the school environment. The majority of students did not feel professionally prepared to respond to unwanted sexual behaviors. Conclusion: These findings demonstrate that sexual harassment can occur in a dental school setting. There is a need for ongoing sexual harassment education programs for students and university staff. Increased knowledge of sexual harassment during graduation can better prepare dental professionals to respond to sexual harassment during their practice.
\end{abstract}

Key words: Sexual harassment. Dentistry. Ethics. Dental students. Social behavior.

\section{INTRODUCTION}

Sexual harassment is an unwelcome deliberate or unintentional action that creates a hostile work environment for the employee ${ }^{24}$. Sexual harassment involves the interpretation of a verbal, nonverbal, or physical action against another person and may refer to an action that is not mutually agreed upon or reciprocated by another individual. This behavior interferes with an individual's work performance and creates an atmosphere of intimidation resulting in a lack of concentration for the victim ${ }^{10}$.

Workplace gender discrimination is illegal in several countries ${ }^{3,23-24}$. In the United States, which is one of the pioneer countries in this kind of legislation, sexual harassment is prohibited by Title VII of the Civil Rights Act of $1964^{23}$. Also, gender discrimination was addressed in academic settings by attaching Title IX amendments to the Educational Act of 1972 that forbid institutions receiving federal funds from discriminating on the basis of $s^{22}$. In Brazil, as well as in several countries of Latin America, sexual harassment is prohibited by the law through the national Penal Code, in the chapter of crimes against sexual freedom ${ }^{3}$; however there is no official recommendation about sexual discrimination in educational environments.

Research during the past 20 years has revealed that sexual harassment is widespread in general society and in higher education, health profession education, and dental education ${ }^{6,15,17-19,27}$. A descriptive study on sexual harassment incidence conducted with more than 8 thousand employees from three Latin America countries revealed that its incidence varied by country and was found to be around $8.7-10 \%$ in Chile, $4.8 \%$ in Brazil and 3.5\% 
in Argentine ${ }^{14}$. Bullying and sexual harassment at school have received recent attention in developed countries, but they have been neglected in Latin America $^{20}$. In a general way, there are few data on the prevalence of sexual harassment in developing countries.

In the dental field, few studies have been published regarding patients and professors and the sexual harassment claims of their students $8,12,16,21,25,27$. There is some evidence that patients may sexually harass their oral health care providers ${ }^{26}$. Information from reports from dental and dental hygiene students indicated that such advances do occur and that providers are rarely educated to deal effectively with them ${ }^{4-5,13}$.

In a study conducted with 300 Oregon dentists and 300 dental hygienists, $44 \%$ of providers experienced one or more patient verbal advances and up to $23 \%$ of providers experienced one or more patient physical advances during a five-year period $^{5}$. These advances were a significant source of concern for many dental professionals.

There is a silence of consent that surrounds sexual harassment. Given the relative paucity of research on issues associated with sexual harassment in academic settings and especially in dental schools, more studies are needed to assess the frequency, type and etiology of sexual harassment involving patients and students or professors and students in the academic dental environment. A more thorough understanding of the causes of sexual harassment and contributing factors will allow academic institutions to implement preventive measures for a situation that is worrying, but often disguised. Accordingly, the purposes of this study were to determine the sexual harassment prevalence in one Brazilian dental school and to evaluate the experiences and attitudes of undergraduate dental students in this academic environment.

\section{MATERIAL AND METHODS}

This project was conducted at Araçatuba Dental School, São Paulo State University (UNESP), Brazil. This cross-sectional study assessed the experiences and attitudes of dental students during the clinical phase of their dental education. The hypothesis was that dental students might be harassed by professors, colleagues and, mainly, by patients receiving treatment from the students.

Data were obtained using an eighteen-item questionnaire that required approximately $15 \mathrm{~min}$ to be completed. The questionnaire consisted of open and closed questions, which were analyzed through the Content Analysis Technique ${ }^{2}$ (qualitative analysis) and frequency distribution (quantitative analysis), respectively. This instrument was pre-tested and it was adapted from other studies reporting on sexual harassment in dental schools and dental environments ${ }^{16,21}$ to the local characteristics (Figure 1). Three questions requested general information (gender, age and year of study) from the students; eleven questions were about students' personal experiences with sexual harassment and 4 questions

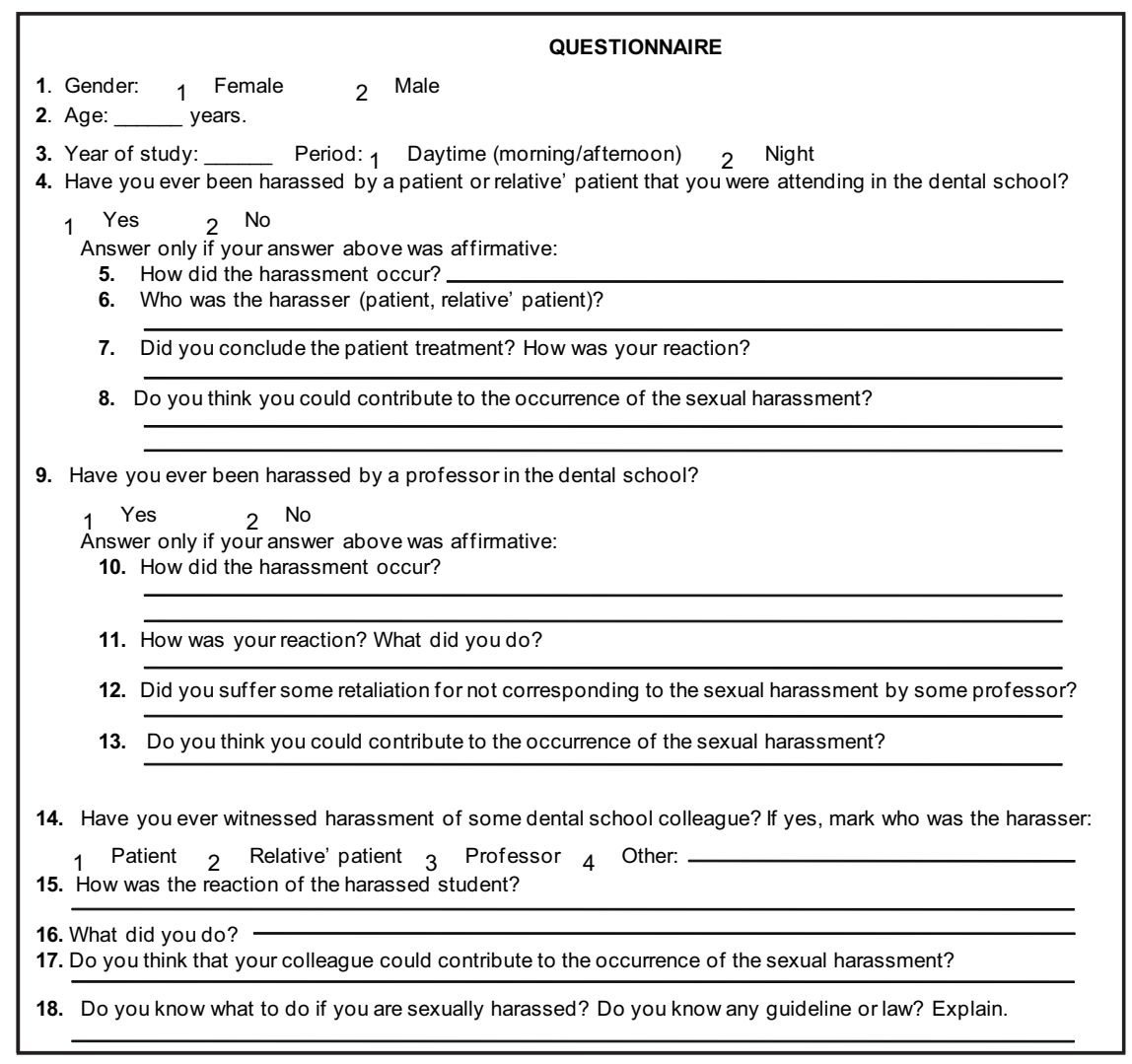

Figure 1- Data collection instrument 
requested information from students who reported they had witnessed someone else being harassed. Students were specifically asked if they had been sexually harassed in dental school; students responding affirmatively were asked to categorize the harasser, and to describe how it occurred. Students were also asked if they had witnessed some colleague being sexually harassed at the dental school; those who answered positively, were asked to categorize the harasser and to describe how it had occurred. A final item asked if they knew what to do in a sexual harassment situation.

A pilot study was carried out with 55 students of a single institution, reporting a completion rate of $92 \%$. Ten percent of the sample, randomly assigned, filled out the same questionnaire 10 days later. Agreement of $80 \%$ was observed. The questionnaire format and students' answers were verified and discussed among researchers, in order to evaluate the adequacy of the instrument.

There were 254 undergraduate students enrolled in the dental school, and all of them were invited to participate in the research. Survey questionnaires were administered to students after a regular class. Students were informed about the purpose of the study and a signed informed consent form was obtained from each participant. A process was followed that assured student anonymity and the confidentiality of their responses. Ten percent of the sample answered twice the questionnaire in order to verify the consistence of answers and an agreement of $89 \%$ was observed.

This study was implemented with methodology that was consistent with the Code of Ethics of the World Medical Association (Declaration of Helsinki) and the research protocol received ethical approval from the Research Ethics Committee of the Araçatuba Dental.

Data entry and analysis were performed by investigators using the statistic software Epi Info version 3.2 (Epi Info, CDC, Atlanta, Georgia, USA). The statistical analysis included two-sample tests,
Chi-square and Fisher's exact tests. A $p$-value of $\leq 0.05$ was required for statistical significance in all tests.

\section{RESULTS}

The sexual harassment questionnaire was completed by 208 students ( $82 \%$ ); 65.9\% females and $34.1 \%$ males. The mean age of dental students was 22 years old, ranging from 19 to 32 years old. The sample was representative of the student population based on the gender (70\% females and $30 \%$ males) and age (mean age 23 years old) in dental education.

Sexual harassment by the patient or a patient's relative as the perpetrator was reported by 19 of all respondents $-9.1 \%$ of study population, including 8 women and 11 men. Table 1 shows different situations in which the sexual harassment occurred. Out of all male students, $15.5 \%$ were harassed at least one time, while $5.9 \%$ of all women were harassed. There was a statistically difference significant between the percentage of all female and male subjects in this study who reported they had been sexually harassed $(p=0.04)$. The probability of male students to be sexually harassed was 3 times as high as that observed for female students (Odds ratio=2.910; 95\% Confidence Interval 1.1137.611).

Out of 19 students harassed by their patients, 16 concluded the treatment. The remaining 3 students refused to treat their patients who were transferred to another dental student for continuation of treatment.

The responses to sexual harassment included ignoring, telling the offending person to stop or telling a tutor what had happened (Table 2). When students who reported harassment by a patient were asked if they had contributed to occurrence of the sexual harassment incident, $37 \%$ said yes, due to a close relationship with the patient, which was misunderstood as intimacy.

Table 1- Sexual harassment experiences reported by dental students who cited the patient as the perpetrator

\begin{tabular}{|c|c|c|c|c|}
\hline \multirow{3}{*}{ Examples of sexual harassment situations } & \multicolumn{4}{|c|}{ Harassed } \\
\hline & \multicolumn{2}{|c|}{ Female } & \multicolumn{2}{|c|}{ Male } \\
\hline & $\mathbf{n}$ & $\%$ & $\mathbf{n}$ & $\%$ \\
\hline $\begin{array}{l}\text { Received unwanted sexual behaviors which were } \\
\text { embarrassing }\end{array}$ & 3 & 37.5 & 4 & 36.6 \\
\hline $\begin{array}{l}\text { Experienced sexual harassment out of the school } \\
\text { setting (such as telephone calling) }\end{array}$ & 4 & 50.0 & 1 & 9.1 \\
\hline $\begin{array}{l}\text { Subject to stories/ jokes which were offensive to } \\
\text { me }\end{array}$ & 1 & 12.5 & 2 & 18.1 \\
\hline Asked for dates, dinner... & 0 & 00.0 & 2 & 18.1 \\
\hline Touched which was uncomfortable & 0 & 00.0 & 2 & 18.1 \\
\hline Total & 8 & 100.0 & 11 & 100.0 \\
\hline
\end{tabular}


Table 2- Responses of dental students who reported being sexually harassed by a patient in the dental care settings

\begin{tabular}{lcr}
\hline Responses to sexual harassment & $\mathbf{n}$ & $\%$ \\
\hline & & \\
\hline Ignored it & 5 & 26.3 \\
\hline Told the offending person to stop & 4 & 21.1 \\
Felt embarrassed & 4 & 21.1 \\
\hline Told a tutor & 2 & 10.5 \\
Had a sexually involvement with the harasser - patient & 1 & 5.3 \\
Recommended to another student to conclude the patient treatment & 3 & 15.7 \\
Total & 19 & 100.0 \\
\hline
\end{tabular}

Table 3- Sexual harassment experiences reported by dental students who cited the professor or the university staff as the perpetrator

\begin{tabular}{|c|c|c|c|c|}
\hline \multirow{3}{*}{ Examples of sexual harassment situations } & \multicolumn{4}{|c|}{ Harassed } \\
\hline & \multicolumn{2}{|c|}{ Female } & \multicolumn{2}{|c|}{ Male } \\
\hline & $\mathbf{n}$ & $\%$ & $\mathbf{n}$ & $\%$ \\
\hline Jokes that have sexual implications & 6 & 60.0 & 1 & 50.0 \\
\hline Asked for dates, dinner... & 1 & 10.0 & 1 & 50.0 \\
\hline Received unwanted sexual behaviors which were embarrassing & 3 & 30.0 & 0 & 00.0 \\
\hline Total & 10 & 100.0 & 2 & 100.0 \\
\hline
\end{tabular}

Twelve students (5.8\%) were sexually harassed by professors or university staff members including 10 female and 2 male students (Table 3). No statistically significant difference in the gender of students harassed by professors or university staff members was observed; however there was a higher prevalence of females who reported harassment by a professor when compared to male students. The sexual insinuations occurred more frequently at the dental school setting (75\%) than in other locations.

When asked how they responded to sexual harassment by university staff members, all students reported they ignored the comments and no one filed a complaint. None of the students who did not respond in a receptive manner to the sexual comments of professors was punished.

The overall prevalence of sexual harassment in the study population of 208 students was $15 \%$; a total of 32 dental students reported that they had been harassed by a patient or a professor/university staff member (Figure 2).

Fifty-three $(25.4 \%)$ out of the 208 students reported that they had witnessed a student colleague being sexually harassed. Patients were cited as harassers in $46.6 \%$ of the cases, followed by faculty members $(44.9 \%)$, university staff members $(3.4 \%)$, other dental student $(3.4 \%)$ and patients' relatives (1.7\%). Responses from harassed students to the situation included feeling embarrassed/terrified (36.5\%), ignoring it (26.9\%), telling the offending person to stop (5.8\%) and recommending the harasser (patient) to be treated

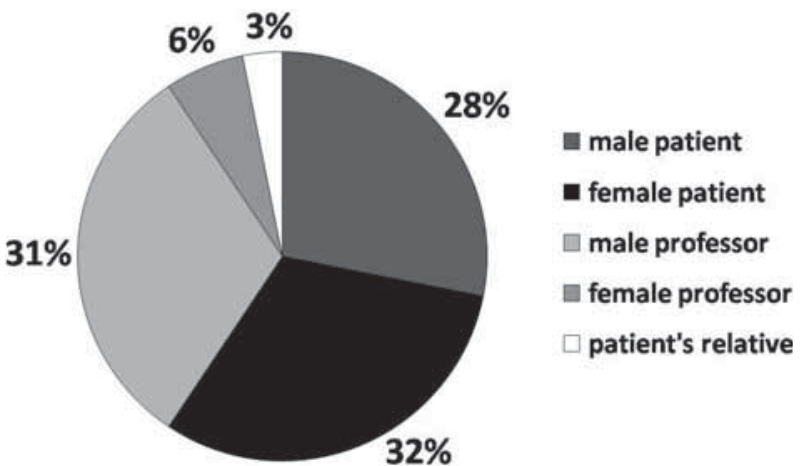

Figure 2- Distribution (\%) of dental students sexually harassed according to perpetrators

by another student (5.8\%). Among students who had witnessed an incident, $73.5 \%$ did nothing to help the harassed colleagues. According to survey respondents who had witnessed an incident, most of the harassed students contributed to the occurrence of sexual harassment because of their own inappropriate behavior or a close relationship with the patient.

Regarding to the dental students' knowledge of legal aspects of sexual harassment, $41.3 \%$ did not know what to do if they were harassed. Among the students $(58.7 \%)$ reporting they knew how to act in a sexual harassment situation, $75.6 \%$ would recourse to a law suit, look for a police station, make a formal complaint or look for a lawyer; $13.9 \%$ would contact a manager on the university or dental school, such as the dean or a university 
staff member; and $7.8 \%$ would ignore the situation and would not look for help.

\section{DISCUSSION}

This is the first study to survey the sexual harassment experiences of undergraduate students in a dental school in Brazil. The prevalence of sexually harassed dental students in our study is similar to that observed in a study conducted at the University of Kentucky ${ }^{12,25}$. When considering the percentage of students that had witnessed a colleague being sexually harassed, the values were also similar to those found by other researchers ${ }^{16,21,27}$.

Although either gender at any position may be the victim of sexual harassment, women who occupy subordinate positions are the most likely targets of these overtures ${ }^{4,12,16,21}$. However, in the present study, men had a higher probability of being sexually harassed than women when the perpetrator was a patient. There is not a clear reason for this difference. One of the hypotheses is that nowadays both men and women can be victims of gender discrimination, and not only women, the "fragile sex", as they were described decades ago.

One limitation of this study was that the data depended on the self-report of students, who defined what constitutes sexual harassment differently according to their personal philosophy, values and life experiences. However, at this first moment, the investigators tried not to influence students in their answers, and preferred not to define sexual harassment previously to students report. In a second phase of this project, students will receive training on sexual and cultural discrimination and harassment, and a new survey will be conducted on sexual harassment prevalence and student's attitudes regarding it.

Sexual harassment behaviors can overlap and some behaviors can be socially acceptable ${ }^{10-11,16}$. Health professionals must be cautious when developing physically close working relationships or using humor, as these behaviors could unintentionally convey sexual overtones. Also, clients could confuse these relationships with intimacy, distorting the meaning of patient-professional relation. The results of this study demonstrated that many students did not worry about certain actions such as being subjected to unwanted sexual attention or listening to sexual comments or jokes; they did not consider these situations to be sexual harassment. The lack of awareness is a strong indication of the necessity of informing dental students and dentists, including faculty members, about the evolving sexual harassment laws and regulations. If dental students were taught sexual harassment prevention and management strategies in the dental educational setting, they would be better prepared to identify illegal behaviors and not tolerate sexual harassment.

It is necessary to define and to discuss with the students and professionals the "hostile working environment". Weinstein, in his article, described scenarios, which are used to help defining and identifying harassment ${ }^{26}$. According to the Brazilian law $^{3}$, the harasser should necessarily be hierarchical superior. This specific characterization for sexual harassment is similarly found in other countries around the world. In this instance, the harasser often occupies a position of power, such as a supervisor or an instructor, to make such demands and to implement a retribution (punishment or penalty) if he/she is not satisfied ${ }^{3}$. However, sexual harassment can occur without a relationship of superiority between the individuals involved, e.g., when the perpetrator is the patient or a relative of the patient and the harassed is the dental student or the dentist. It is difficult for an employee or a student to perform his job adequately in this kind of "hostile working environment". It is extremely important to prepare the future health professionals to respond to harassing incidents with standards of professionalism, especially when the national laws do not protect against this situation.

Sexual harassment situations were similar in Brazil and other countries, as reported in previous studies $8,16,21,25,27$. The majority of complaints come from women; however the number of complaints filed by men is increasing, along with increasing numbers of men filing against female supervisors. Two specific situations can be described as most prevalent in the workplace:

1) "Something for something"; this is the "you do something for me and I'll do something for you" type of exchange. This occurs when a job benefit is directly tied to an employee submitting to unwelcome sexual advances. For example, a supervisor promises an employee a raise if she will go out on a date with him, or tells an employee she will be fired if she doesn't sleep with him - in the dental environment, this could correspond to sexual favors in exchange for better grades or final approval in the school year.

2) Hostile Environment Sexual Harassment: this occurs when an employee is subjected to comments of a sexual nature, offensive sexual materials, or unwelcome physical contact as a regular part of the work environment. In a general way, a single isolated incident will not be considered hostile environment harassment unless it is extremely outrageous and egregious conduct. In the present study, the students did not consider a sexual harassment problem being invited for a date or being subjected to some jokes, even if their content was sexually aggressive.

A concern is that, in addition to being illegal, these experiences are damaging because they may cause students to become less idealistic and more cynical as they progress through their dental education, and later in their clinical practice ${ }^{15}$.

The percentage of victims who actually file formal sexual harassment complaints is extremely low $6,12,16,21,24-25$. The Brazilian dental students 
participating in this study failed to report it because of lack of information. The majority of students did not feel professionally prepared to respond to unwanted sexual behaviors and they were not aware of any guidelines or polices in the dental setting that describe how to respond to sexually motivated harassment. High levels of anxiety among dental students have been frequently described in the literature and could be a sign of silent problems, such as sexual harassment situations, which are usually not reported by the involved subjects ${ }^{1}$.

Taking into account the documented instances of sexual harassment in the health care professions ${ }^{5,7,16,26-27}$, medical, dental, nursing, and physical therapy schools should develop programs to educate students about this problem. It is essential to help dental students understand what sexual harassment is and what kind of behaviors are tolerated, to clarify what they can do individually in order to reduce the probability of experiencing sexual harassment, and to suggest ways to respond if they do find themselves or another individual in a situation in which sexual harassment is occurring. Sexual harassment awareness programs have been developed in medical ${ }^{9}$ and dental ${ }^{12}$ schools in the United States, and could serve as models for other countries where training programs focusing on sexual and cultural discrimination and harassment are still in their formative stages in higher education institutions. Such programs can prepare future professionals to be proactive in providing an appropriate protocol to use whenever they perceive sexual harassment in the workplace.

\section{CONCLUSION}

The findings of this study show the prevalence of sexual harassment among dental students at one dental school in Brazil. In order of frequency, the harassers were reported to be the patients, relatives of patients and professors, as well as other students. Information about managing sexual harassment needs to be incorporated into the dental curricula. Furthermore, it is important to arm students with the knowledge to be proactive in creating an environment that minimizes the probability of sexual harassment by having assertive definitions of acceptable behavior, learning how to anticipate situations, and responding to sexual harassment when it occurs as well as reporting these incidents to appropriate individuals in the dental school.

\section{ACKNOWLEDGMENTS}

The authors extend their gratitude to the administration, principals and professors of Araçatuba Dental School, São Paulo State University (UNESP) as well as to the participating undergraduate students. We also gratefully acknowledge the support from the Postgraduate
Program in Preventive and Community Dentistry of this University.

\section{REFERENCES}

1- Al-Omari WM, Al-Omiri MK. Dental anxiety among university students and its correlation with their field of study. J Apppl Oral Sci. 2009;17(3):199-203.

2- Bardin L. Análise de Conteúdo. 3. ed. São Paulo: Ed. 70; 2004. 3- Brasil. Código Penal. Decreto-Lei 2848 de 7/12/1940. 5.ed. São Paulo: Editora Revista Tribunal; 2003. p. 336.

4- Chiodo GT, Tolle SW, Critchlow C. Sexual boundaries in dental practice. Part 2. Gen Dent. 1999;47(6):552-7.

5- Chiodo GT, Tolle SW, Labby D. Sexual advances by patients in dental practice: implications for the dental and dental hygiene curricula. J Dent Educ. 1992;56(9):617-24.

6- Daugherty SR, Baldwin DC Jr, Rowley BD. Learning, satisfaction and mistreatment during medical internship: a national survey of working conditions. JAMA. 1998;279(15):1194-9.

7- deMayo RA. Patient sexual behaviors and sexual harassment: a national survey of physical therapists. Phys Ther. 1997;77(7):73944.

8- Duley SI, Fitzpatrick PG, Zornosa X, Lambert CA, Mitchell A. Dental hygiene students' attitudes towards ethical dilemmas in practice. J Dent Educ. 2009;73(3):345-57.

9- Feldman $\mathrm{P}$, Jones $\mathrm{S}$, Shrier I. Eradicating sexual harassment during medical training. Acad Med. 1997;72(12):1026-7.

10- Fiske ST, Glick P. Ambivalence and stereotypes cause sexual harassment: A theory with implications for organizational change. J Soc Iss. $1995 ; 51: 97-115$.

11- Jorgenson L, Hirsch A. Sexual contact between dentist and patient: is dating ethical? CDS Rev. 1994;87(7):24-7.

12- Lillich TT, Webster DB, Marshall EO, Smith TA, Seaver DC, Szeluga MA. The influence of a workshop on dental students' perceptions about sexual harassment. J Dent Educ. 2000;64(6):401-8.

13- Loring R. Sexual harassment in the dental office: an assessment. CDS Rev. 1994;87(7):20-2.

14- Merkin RS. Cross-cultural differences in perceiving sexual harassment: demographic incidence rates of sexual harassment/ sexual aggression in Latin America. North Am J Psychology. 2008; 10:277-89.

15- Nora LM. Sexual harassment in medical education: a review of the literature with comments from the law. Acad Med. 1996;71(1Suppl):S113-8.

16- Pennington A, Darby M, Bauman D, Plichta S, Schnuth ML. Sexual harassment in dentistry: experiences of Virginia dental hygienists. J Dent Hyg. 2000;74(4):288-95.

17- Richman JA, Rospenda KM, Nawym SJ, Flaherty JA, Fendrich $M$, Drum $M L$, et al. Sexual harassment and generalized workplace abuse among university employees: prevalence and mental health correlates. Am J Public Health. 1999;89(3):358-63.

18- Sfikas PM. Sexual harassment and vicarious liability. J Am Dent Assoc. 2005;136(6):809-11.

19- Sfikas PM. Who's liable when an employee quits because of sexual harassment? Supreme Court to rule on employers' liability for supervisors' conduct. J Am Dent Assoc. 2004;135(5):657-60. 20- Souza ER, Ribeiro J. Bullying and sexual harassment among Brazilian high school students. J Interpers Violence. 2005;20(9):1018-38

21- Telles-Irvin P, Schwartz IS. Sexual harassment among female dentists and dental students in Texas. J Dent Educ. $1992 ; 56(9): 612-6$.

22- U.S.A. Department of Education. Title IX of the Educational Amendments of 1972 (20 U.S.C. Sec. 1681-88).

23- U.S.A. Equal Employment Opportunity Commission. Final amendment to guidelines on discrimination because of sex under Title VII of the Civil Rights Act of 1964, as amended. 29 CFR Section 1604.11(b) Federal Register 1980;45:25024-5.

24- Webb SL. Sexual harassment shades of gray: Sexual harassment: Resource Manual. Seattle: Premiere; 1994. p. 1-105. 25- Webster DB, Smith TA, Marshall EO, Seaver DC, Szeluga MA, Lillitch TT. Dental students' sexual harassment experiences and attitudes. J Dent Educ. 1999;63(9):665-72.

26- Weinstein BD. Sexual harassment: identifying it in dentistry. J Am Dent Assoc. 1994;125(7):1016-21.

27- Wolf TM, Scurria PL, Bruno AB, Butler JA. Perceived mistreatment of graduating dental students: a retrospective study. J Dent Educ. 1992;56(5):312-6. 